\title{
HUMAN PAPILLOMAVIRUS VACCINE - KNOWLEDGE AND ATTITUDES AMONG PARENTS OF CHILDREN AGED 10-14 YEARS: A CROSS-SECTIONAL STUDY, TÎRGU MUREŞ, ROMANIA
}

\author{
Septimiu Voidăzan ${ }^{1}$, Monica Tarcea², Silviu-Horia Morariu ${ }^{3}$, Adelina Grigore ${ }^{4}$, Minodora Dobreanu ${ }^{5}$ \\ 'Department of Epidemiology, University of Medicine and Pharmacy of Tîrgu Mureş, Romania \\ ${ }^{2}$ Department of Community Nutrition, University of Medicine and Pharmacy of Tîrgu Mureş, Romania \\ ${ }^{3}$ Department of Dermatology, University of Medicine and Pharmacy of Tîrgu Mureş, Romania \\ ${ }^{4}$ University of Medicine and Pharmacy of Tîrgu Mureş, Romania \\ ${ }^{5}$ Department of Laboratory Medicine, University of Medicine and Pharmacy of Tîrgu Mureş, Romania
}

\section{SUMMARY}

Aim: Romania ranks first in Europe in terms of mortality from cervical cancer, recording 6.3 times more deaths than the mean in EU countries. Although vaccination campaigns were launched by health officials in Romania, the acceptance rate remained insignificant and programmes were discontinued. A successful vaccination programme requires a high rate of acceptance and accurate information for health professionals and parents. The aim of the study was to evaluate the level of parental knowledge about human papilomavirus (HPV) infection and HPV vaccination including the information obtained from general practitioners and identification of barriers in implementing a vaccination strategy.

Methods: We performed a cross-sectional study using a self-administered questionnaire for the parents of pupils in grades $5-8$, in three randomly selected secondary schools in Tîrgu Mureş, Romania.

Results: We surveyed 918 parents. Of the respondents, $85.8 \%$ have heard of HPV infection. Most reported an average level of knowledge about HPV infection and HPV vaccination. The two main sources of information were specialized healthcare professionals ( $42.8 \%$ for HPV infection, $39.1 \%$ for HPV vaccination) and the Internet browsing ( $42.3 \%$ and $42.9 \%$, respectively). Based on current knowledge, only one third of parents would have their child vaccinated against HPV infection. According to most parents surveyed, the main reasons for not wanting to have their child vaccinated is the fear of side effects; the vaccine is new and insufficiently studied; or parents do not know details about the vaccine.

Conclusions: The parents showed the average level of knowledge about HPV infection and HPV vaccination. The implementation of an effective programme to increase the acceptance rate of HPV vaccination requires educational strategies aimed at involving parents and their children and supported by general practitioners and public health professionals.

Key words: HPV infection, cervical cancer, HPV vaccination, questionnaire, parents

Address for correspondence: M. Tarcea, University of Medicine and Pharmacy Tirgu-Mures 38 Gh. Marinescu street, 540139 Tirgu-Mures, Romania. E-mail: monica.tarcea@umftgm.ro

http://dx.doi.org/10.21101/cejph.a4287

\section{INTRODUCTION}

Infection with human papillomavirus (HPV) is one of the most common sexually transmitted infections around the world. It is associated with cervical cancer in $99.7 \%$ of all cases, and is considered the leading cause of this type of cancer $(1,2)$.

The role of high-risk HPV genotypes (16 and 18) has been proven in the aetiology of cervical cancer accounting for approximately $70 \%$ of all cases, as well as for significant health problems in men, including anal, penile and oro-pharyngeal cancers, while the low-risk genotypes in both sexes may cause genital warts and respiratory papillomatosis $(3,4)$.

Cervical cancer is the fourth most common cancer in women, the seventh of all cancers, with an estimated incidence rate of 560,000 cases in 2015. A great majority of cases (about $85 \%$ ) were diagnosed in less developed regions, including East Africa, South Africa, the Middle East, and Eastern Europe. In 2012, approximately 266,000 deaths from cervical cancer were recorded worldwide, accounting for $7.5 \%$ of all cancer deaths in women. Nearly nine in ten $(87 \%)$ deaths from cervical cancer occurred in less developed regions (5).

Vaccination against HPV infection effective for genotypes 6, 11,16 and 18 brought hope of reducing the incidence of infections, HPV-related morbidity and mortality. The latest recommendations include vaccination of adolescents and young adult women aged between 9 and 26 years and eligible men of similar ages to reduce their likelihood of getting genital warts and to prevent cancer (6).

Two vaccines were licensed in 2006/2007 for the prevention of cervical cancer (7). Quadrivalent vaccine (GardasilVR, Merck \& Co., Inc.) showed $99 \%$ protection against HPV genotypes 16 and 
18 associated with CIN 2/3 and adenocarcinoma in situ among women aged 15-26 years, and against condyloma acuminata (genital warts) caused by HPV genotypes 6 and 11. It is recommended that three doses of Gardasil should be used $(8,9)$. The other vaccine, Cervarix ${ }^{\mathrm{TM}}$ (GlaxoSmithKline) is a bivalent vaccine against HPV 16 and HPV 18 genotypes, for which three doses are also recommended: one administered initially, the second at one month, and the third at six months (10).

Romania ranks first in Europe in terms of mortality from cervical cancer $(10.77 \%$ per 100,000$), 6.3$ times higher than the mean of EU countries. Of all cancers in women, cervical cancer ranks fourth in terms of mortality after breast, colorectal and lung cancer. The highest mortality rates are found in the age groups of $50-60(32.9 \%$ per 100,000$), 60-70(37.3 \%$ per 100,000$)$, and $70-80(38.5 \%$ per 100,000$)$. The incidence rate was an estimated $28.65 \%$ per 100,000 , with 4,000 new cases discovered after 2012 , ranking this type of cancer as the third after breast and colorectal cancer. The highest incidence rates were found in the age groups of $50-60(82.1 \%$ per 100,000$), 60-70(69.0 \%$ per 100,000$)$, and $40-50(60.1 \%$ per 100,000$)(5)$.

A voluntary campaign for immunization against HPV types 16 and 18 was introduced in 2008 targeting girls aged 10-11 years. However, a very small percentage of girls were vaccinated. Although there have been other attempts at vaccination launched by healthcare officials in Romania, the acceptance rate remained insignificant and programmes were discontinued $(11,12)$. A successful vaccination programme requires a high rate of acceptance and accurate information targeting both health professionals and parents.

The aim of this article is to assess the level of parental knowledge about HPV infection and HPV vaccination, including the degree of information from general practitioners (GP), and the identification of barriers in implementing a vaccination strategy.

\section{MATERIALS AND METHODS}

We performed a cross-sectional study using the self-administered questionnaire for the parents of pupils in grades 5-8, in three randomly selected secondary schools in Tîrgu Mureş, Romania, a city with a population of approximately 134,000. According to the 2011 census, the ethnic distribution of the population showed $52.0 \%$ of Romanians, $44.9 \%$ of Hungarians and $2.5 \%$ of Roma population. The secondary schools included in the study had a total of 1,180 students in grades $5-8$, which represented about $10.0 \%$ of 5-8 grades pupils in the city. The questionnaire included 34 items with questions about demographic information, attitudes towards the prevention of serious diseases, knowledge about the infection, degree of information received from general practitioners about cervical cancer, awareness about the vaccine that prevents HPV infection, barriers/reasons for non-vaccination, perception of the risk that one's daughter could contract HPV, intention to have one's daughter vaccinated in the future, and intention to benefit from the immunization programme by vaccination against HPV. The questions were mostly open-ended, closed-ended with ordered answers, closed-ended with unordered answers, but also binary questions with a maximum time of 15 minutes to complete.

There were instructions for each question regarding the type of answers: single or multiple. The header of the questionnaire included the purpose of the study, assurance of anonymity and confidentiality of the answers. Hungarian parents were given questionnaires translated into Hungarian (36.0\%). The study was approved by the Ethics Committee of the University of Medicine and Pharmacy of Tîrgu Mureş, Romania.

\section{Data Collection}

The survey was conducted in October-December 2014. We targeted a representative sample of 1,100 students in three major districts of the city of Tîrgu Mureş to allow significant statistical comparisons. An agreement on collaboration between the University of Medicine and Pharmacy of Tîrgu Mureş and the Mureş County School Inspectorate was reached, a protocol which, along with study procedures and information documents (scope, objectives, working steps), was presented to the educational coordinators and to the teachers of grades 5-8 in the selected schools. The teachers distributed the questionnaires in a sealed envelope which the students handed to their parents. Each teacher monitored and kept track of each questionnaire and within a maximum of two weeks after administration, the completed questionnaires were collected. From 1,100 administered questionnaires, 918 parents agreed to participate in the study representing a response rate of $83.4 \%$. The 918 completed questionnaires were entered into an Excel database and processed statistically.

\section{Statistical Analysis}

Statistical analysis was performed using the Statistical Package for Social Sciences (SPSS, version 20, Chicago, IL, USA). Student t-test was used to assess the differences between the means of continuous variables (mean $\pm \mathrm{SD}$ ), while $\chi^{2}$ test was used for categorical variables. Bivariate analysis (chi square tests) was used to assess the associations between each of the independent characteristics and the different variables of interest. After bivariate analysis, only those results that proved reliable ( $p$ value $\leq 0.05$ ) were introduced in the multivariate logistic regression models to model cumulative associations between independent characteristics and dichotomous and continuous results of interest. Odds ratios $(\mathrm{OR})$ and confidence intervals $(95 \% \mathrm{CI})$ were presented in the logistic regression models. All tests were interpreted in relation to statistical significance $\mathrm{p}=0.05$ and statistical significance was considered for $\mathrm{p}$ values under the significance threshold.

\section{RESULTS}

\section{Participants}

Nearly two thirds of the respondents were female, mean age 40 years (age range from 28-57 years), and most of them were married $(85.7 \%)$. About one third of the mothers surveyed were high school graduates, another third had attained a university degree, and about $14 \%$ had completed up to 10 grades. The ratio of fathers with a high school diploma or a university degree was similar to the mothers' one, however, the percentage of fathers who had completed up to 10 grades was higher $(24.3 \%)$. The distribution into ethnic groups revealed $66 \%$ of Romanians, $33.3 \%$ of Hungarians and $0.7 \%$ Roma population. Almost all of 
the respondents $(98.5 \%)$ were registered with GP, with $74.4 \%$ of children registered with the same GP as their parents, while $25.4 \%$ were registered with another GP.

\section{General Attitude towards Prevention of Infectious Diseases}

In reply to the following questions: "What is your attitude towards a health problem occurring in children?" The respondents (93.4\%) answered that they relied on healthcare professionals, and a small proportion asked for the advice of a chemist or administered the child a drug they were familiar with. And "What is your attitude towards prevention of serious diseases?": The respondents (67.0\%) considered the prevention of serious diseases as a mandatory step; $13.0 \%$ agreed that more free vaccines should be made available; $17.4 \%$ preferred to have their child vaccinated so that the child would not develop the disease; and $9.6 \%$ would not have their child vaccinated preferring to have their child's immunity developed by natural infection. Approximately $86.0 \%$ of parents know at least two vaccines that are included in the National Immunization Programme (NIP), and $89.1 \%$ confirmed that their child received at least one vaccine included in NIP. According to the parents, the reasons why they did not want to have their child vaccinated were the following: $68.1 \%$ feared side effects, $28.2 \%$ were in doubt regarding the safety or efficacy of vaccine, and $22.1 \%$ did not know details or were otherwise poorly informed about the vaccine.

\section{Knowledge of HPV infection and HPV vaccination}

Of all the respondents, $85.8 \%$ had heard of the infection and $85-91.4 \%$ of those who answered the question about the ways of transmission of the infection mentioned heterosexual or homosexual relationships, 57.6-70\% cutaneous transmission (touching warts or intimate touch). However, there were incorrect answers, according to some respondents the infection is transmitted through WC (43.7\%), public baths or swimming pools (47.4\%), kiss (30.5\%), blood transfusion (68.9\%), unsterilized needles $(67.5 \%)$, or contaminated objects (59\%). Regarding the perceived severity, the respondents believed that the infection caused cervical cancer $(82.9 \%)$ and genital warts (30.5\%). On a scale from 1 (insufficient) to 5 (excellent), the respondents' level of knowledge about HPV infection averaged 3 (good), varying to 2 (satisfactory: 26\%) or to 4 (very good: $24.4 \%$ ). Conversely, $62.3 \%$ of the respondents knowledge about HPV vaccination was satisfactory to good. Tables 1 and 2 present the statistical associations between the degrees of the level of knowledge (HPV infection or vaccination) and sociodemographic characteristics. Regarding HPV infection, women are slightly better informed than men $(p=0.001)$, but not about HPV vaccination. Higher educational background (high school, post-secondary, university), both in women and men correlated with higher levels of knowledge about the infection or vaccination.

Marital status was not a criterion with significant differences in correlation with HPV vaccination, only with the infection, cohabiting or unmarried people being better informed.

Respondents registered with GP knew additional information about both issues addressed, compared with individuals not registered with GP. Higher level of knowledge is also evident in $26.4 \%$ of parents who requested information when addressing their GP about HPV infection $(p=0.0001)$ or HPV vaccination $(p=0.0001)$.
The two main sources of information on HPV infection or HPV vaccination were specialized healthcare professionals $(42.8 \%$ and $39.1 \%$, respectively) or by browsing the Internet $(42.3 \%$ and $42.9 \%$, respectively). Information of similar quality to that offered by healthcare professionals, both about infection and about vaccination, was derived from reading books, but only one fifth of respondents used this source. Newspapers, radio, television shows, even if used by one third of the respondents (32.9\%), did not improve the quality of information rather being associated with a level 2 (sufficient) or 3 (good) on the knowledge scale. School (9.3\%), whether we consider secondary or high school, also did not turn out as one of the main sources of information.

About one third of the parents would have their child vaccinated against HPV infection. The knowledge of these parents on the subject is significantly higher than that of parents who would not have their child vaccinated with this vaccine $(\mathrm{p}=0.0001)$.

The main reason why parents would have their daughter vaccinated is the prevention of HPV infection and cervical cancer protection. Other parents would rely on this solution "if they knew more about the side effects and contraindications of the vaccine"; "only after having thoroughly documented its side effects"; or "if they had enough positive information". The percentage of parents who would not have their daughter vaccinated is very high: $64.4 \%$. The main reasons against vaccination are "the fear of side effects" or "the novelty of the vaccine and more research is needed to prove its efficacy and lack of side effects". Some parents "would prefer to explain to their child all the methods of protection and prevention because they believe that vaccination is not the best method of prevention". Many parents also mentioned that "the population is not well-informed about HPV vaccination".

By a univariate statistical analysis, Table 3 shows the conditions recommended for vaccination against HPV infection. About $42 \%$ of parents whose source of information was healthcare professionals are positive about having their daughter vaccinated $(p=0.009)$. Other sources of information, some with lower impact (friends, school) and others with a higher impact (books, mass media, the Internet), do not significantly influence vaccination. Of the few people who have requested information from GP, about $44.2 \%$ would decide positively about vaccination $(p=0.001)$. The pertinent information provided by GP is crucial in the parent's decision to have the child vaccinated with this type of vaccine. Statistical significance can be identified in line with variants in the questionnaire used to identify the role of GP in debates on this topic. Thus, GP frequently mentions that almost all cervical cancers are caused by HPV infection $(40.3 \%)$ or by HPV infection prevention methods $(37.2 \%)$. The decision regarding vaccination was strongly influenced if the parent had received information about HPV infection prevention methods ( $p=0.001$ ), about HPV vaccination recommendations $(p=0.001)$, or about the benefits of the vaccine $(p=0.001)$. In addition to the information provided by GP, the knowledge gained about vaccination, the desire to learn the necessity of vaccination $(p=0.001)$, complete protection $(p=0.001)$, precaution to others $(p=0.001)$, or family history of cancer $(p=0.001)$ largely influenced the parents' attitude towards vaccination $(63.9-68.8 \%)$.

Table 4 shows the results of a multivariate analysis by logistic regression to identify factors that would influence the parents' decision to have their daughter vaccinated, with $35.6 \%$ of parents 
Table 1. The respondents' degrees of the level of knowledge about HPV infection according to socio-demographic characteristics and the source of information $(N=918)$

\begin{tabular}{|c|c|c|c|c|c|c|}
\hline \multicolumn{7}{|c|}{ How would you rate the degree of your knowledge about HPV infection on a scale of 1 to $5 ?^{*}$} \\
\hline & $\begin{array}{c}1 \\
n=101 \\
(11.0 \%)\end{array}$ & $\begin{array}{c}2 \\
n=239 \\
(26.0 \%)\end{array}$ & $\begin{array}{c}3 \\
n=290 \\
(31.6 \%)\end{array}$ & $\begin{array}{c}4 \\
\mathrm{n}=224 \\
(24.4 \%)\end{array}$ & $\begin{array}{c}5 \\
n=64 \\
(7.0 \%)\end{array}$ & $\mathrm{p}$ value \\
\hline \multicolumn{7}{|l|}{ Gender (\%) } \\
\hline Female $(60.1 \%)$ & 11.6 & 21.9 & 30.8 & 27.5 & 8.2 & \multirow{2}{*}{0.001} \\
\hline Male (39.9\%) & 10.1 & 32.2 & 32.8 & 19.7 & 5.2 & \\
\hline \multicolumn{7}{|l|}{ Mother's level of education (\%) } \\
\hline Primary school (four grades, $1.2 \%$ ) & 40.0 & 50.0 & 0.0 & 0.0 & 10.0 & \multirow{5}{*}{$<0.001$} \\
\hline Secondary school (grades 5-10, 12.6\%) & 13.1 & 32.7 & 31.8 & 17.8 & 4.7 & \\
\hline High school (34.7\%) & 14.2 & 32.9 & 31.5 & 18.0 & 3.4 & \\
\hline Post-secondary school (18.0\%) & 4.6 & 18.3 & 32.0 & 35.3 & 9.8 & \\
\hline Higher education (33.6\%) & 9.4 & 16.8 & 34.3 & 29.0 & 10.5 & \\
\hline \multicolumn{7}{|l|}{ Father's level of education (\%) } \\
\hline Primary school (four grades, $1.7 \%$ ) & 11.1 & 44.4 & 33.3 & 11.1 & 0.0 & \multirow{5}{*}{$<0.001$} \\
\hline Secondary school (grades 5-10, 22.6\%) & 15.0 & 33.3 & 30.8 & 19.2 & 1.7 & \\
\hline High school (31.3\%) & 11.4 & 24.1 & 33.7 & 26.5 & 4.2 & \\
\hline Post-secondary school (12.3\%) & 13.8 & 29.2 & 29.2 & 23.1 & 4.6 & \\
\hline Higher education (32.1\%) & 7.6 & 14.1 & 32.4 & 32.9 & 12.9 & \\
\hline \multicolumn{7}{|l|}{ Marital status (\%) } \\
\hline Single (2.5\%) & 8.7 & 30.4 & 17.4 & 43.5 & 0.0 & \multirow{4}{*}{0.003} \\
\hline Married $(85.7 \%)$ & 11.8 & 23.9 & 33.2 & 23.8 & 7.4 & \\
\hline Divorced (8.8\%) & 6.2 & 43.2 & 28.4 & 17.3 & 4.9 & \\
\hline Cohabiting (2.1\%) & 5.3 & 31.6 & 10.5 & 42.1 & 10.5 & \\
\hline \multicolumn{7}{|l|}{ Ethnic distribution (\%) } \\
\hline Romanian $(66.0 \%)$ & 12.0 & 20.8 & 31.0 & 28.4 & 7.8 & \multirow{3}{*}{$<0.001$} \\
\hline Hungarian (33.3\%) & 8.2 & 36.6 & 33.3 & 16.3 & 5.6 & \\
\hline Roma $(0.7 \%)$ & 50.0 & 16.7 & 0.0 & 33.3 & 0.0 & \\
\hline \multicolumn{7}{|l|}{ Are you registered with GP? (\%) } \\
\hline Yes $(98.5 \%)$ & 11.2 & 26.0 & 31.6 & 24.6 & 6.6 & \multirow{2}{*}{0.01} \\
\hline No $(1.5 \%)$ & 0.0 & 28.6 & 28.6 & 14.3 & 28.6 & \\
\hline \multicolumn{7}{|c|}{ Have you requested information from your GP about HPV infection? (\%) } \\
\hline Yes $(26.4 \%)$ & 6.2 & 16.9 & 32.2 & 31.4 & 13.2 & \multirow{2}{*}{$<0.001$} \\
\hline No $(73.6 \%)$ & 12.7 & 29.3 & 31.4 & 21.9 & 4.7 & \\
\hline \multicolumn{7}{|c|}{ Which were the two main sources of information on HPV infection? (\%) } \\
\hline Healthcare professionals (42.8\%) & 5.9 & 19.6 & 31.6 & 31.9 & 11.0 & $<0.001$ \\
\hline Parents, relatives $(4 \%)$ & 5.7 & 34.3 & 28.6 & 22.9 & 8.6 & ns \\
\hline Friends $(10.9 \%)$ & 10.5 & 36.8 & 36.8 & 15.8 & 0.0 & 0.005 \\
\hline Books, magazines $(22.5 \%)$ & 2.6 & 15.3 & 35.7 & 36.2 & 10.2 & $<0.001$ \\
\hline Newspapers, radio, TV (32.9\%) & 10.8 & 33,8 & 32.8 & 20.2 & 2.4 & $<0.001$ \\
\hline School (9.3\%) & 17.3 & 23.5 & 32.1 & 21.0 & 6.2 & ns \\
\hline Internet (42.3\%) & 5.4 & 22.8 & 40.1 & 28,5 & 3.3 & $<0.001$ \\
\hline \multicolumn{7}{|c|}{ Would you have your daughter vaccinated against HPV infection? (\%) } \\
\hline Yes $(35.6 \%)$ & 8.6 & 24.2 & 32.1 & 29.7 & 5.5 & \multirow{2}{*}{0.02} \\
\hline No $(64.4 \%)$ & 12.4 & 27.1 & 31.3 & 21.5 & 7.8 & \\
\hline
\end{tabular}

*1 - unsatisfactory, 2 - satisfactory, 3 - good, 4 - very good, 5 - excellent 
Table 2. The distribution of the level of knowledge about HPV vaccination among the respondents according to socio-demographic characteristics and the source of information $(N=918)$

How would you rate the degree of your knowledge about HPV vaccination on a scale of 1 to 5 ? $^{\star}$

\begin{tabular}{|c|c|c|c|c|c|c|}
\hline & $\begin{array}{c}1 \\
n=136 \\
(14.8 \%)\end{array}$ & $\begin{array}{c}2 \\
n=291 \\
(31.7 \%)\end{array}$ & $\begin{array}{c}3 \\
n=281 \\
(30.6 \%)\end{array}$ & $\begin{array}{c}4 \\
n=169 \\
(18.4 \%)\end{array}$ & $\begin{array}{c}5 \\
n=41 \\
(4.5 \%)\end{array}$ & $p$ value \\
\hline \multicolumn{7}{|l|}{ Gender (\%) } \\
\hline Female $(60.1 \%)$ & 14.5 & 29.0 & 33.2 & 18.5 & 4.9 & \multirow{2}{*}{ ns } \\
\hline Male (39.9\%) & 15.3 & 35.8 & 26.8 & 18.3 & 3.8 & \\
\hline \multicolumn{7}{|l|}{ Mother's level of education (\%) } \\
\hline Primary school (four grades, $1.2 \%$ ) & 60.0 & 20.0 & 0.0 & 0.0 & 20.0 & \multirow{5}{*}{$<0.001$} \\
\hline Secondary school (grades 5-10, 12.6\%) & 19.6 & 38.3 & 27.1 & 13.1 & 1.9 & \\
\hline High school (34.7\%) & 18.0 & 35.3 & 27.5 & 15.9 & 3.4 & \\
\hline Post-secondary school (18.0\%) & 7.2 & 27.5 & 30.7 & 29.4 & 5.2 & \\
\hline Higher education (33.6\%) & 11.9 & 25.9 & 37.8 & 18.2 & 6.3 & \\
\hline \multicolumn{7}{|l|}{ Father's level of education (\%) } \\
\hline Primary school (four grades, $1.7 \%$ ) & 11.1 & 44.4 & 33.3 & 11.1 & 0.0 & \multirow{5}{*}{0.008} \\
\hline Secondary school (grades 5-10, 22.6\%) & 23.3 & 39.2 & 20.8 & 15.8 & 0.8 & \\
\hline High school (31.3\%) & 11.4 & 33.1 & 34.3 & 18.7 & 2.4 & \\
\hline Post-secondary school (12.3\%) & 12.3 & 32.3 & 32.3 & 20.0 & 3.1 & \\
\hline Higher education (32.1\%) & 13.5 & 21.8 & 32.9 & 24.7 & 7.1 & \\
\hline \multicolumn{7}{|l|}{ Marital status (\%) } \\
\hline Single $(2.5 \%)$ & 26.1 & 43.5 & 21.7 & 8.7 & 0.0 & \multirow{4}{*}{ ns } \\
\hline Married $(85.7 \%)$ & 15.0 & 29.9 & 31.3 & 19.2 & 4.7 & \\
\hline Divorced $(8.8 \%)$ & 9.9 & 46.9 & 24.7 & 16.0 & 2.5 & \\
\hline Cohabiting (2.1\%) & 10.5 & 31.6 & 42.1 & 5.3 & 10.5 & \\
\hline \multicolumn{7}{|l|}{ Ethnic distribution (\%) } \\
\hline Romanian $(66.0 \%)$ & 14.2 & 29.2 & 32.8 & 18.8 & 5.0 & \multirow{3}{*}{0.05} \\
\hline Hungarian (33.3\%) & 15.4 & 36.9 & 26.8 & 17.3 & 3.6 & \\
\hline Roma $(0.7 \%)$ & 50.0 & 16.7 & 0.0 & 33.3 & 0.0 & \\
\hline \multicolumn{7}{|l|}{ Are you registered with GP? (\%) } \\
\hline Yes $(98.5 \%)$ & 15.0 & 31.5 & 30.6 & 18.6 & 4.2 & \multirow{2}{*}{0.01} \\
\hline № $(1.5 \%)$ & 0.0 & 42.9 & 28.6 & 7.1 & 21.4 & \\
\hline \multicolumn{7}{|c|}{ Have you requested information from your GP about HPV vaccination? (\%) } \\
\hline Yes $(26.4 \%)$ & 7.9 & 17.4 & 36.0 & 28.1 & 10.7 & \multirow{2}{*}{$<0.001$} \\
\hline No $(73.6 \%)$ & 17.3 & 36.8 & 28.7 & 14.9 & 2.2 & \\
\hline \multicolumn{7}{|c|}{ Which were the two main sources of information on HPV vaccination? (\%) } \\
\hline Healthcare professionals (39.1\%) & 7.2 & 23.4 & 36.2 & 26.2 & 7.0 & $<0.001$ \\
\hline Parents, relatives (3.1\%) & 28.6 & 39.3 & 14.3 & 10.7 & 7.1 & 0.04 \\
\hline Friends $(11.7 \%)$ & 15.0 & 37.4 & 32.7 & 13.1 & 1.9 & ns \\
\hline Books, magazines $(21.9 \%)$ & 9.9 & 18.3 & 38.6 & 25.7 & 7.4 & $<0.001$ \\
\hline Newspapers, radio, TV (32.4\%) & 15.8 & 40.4 & 26.6 & 15.2 & 2.0 & $<0.001$ \\
\hline School (7.6) & 17.1 & 44.3 & 21.4 & 14.3 & 2.9 & ns \\
\hline Internet (42.9\%) & 9.4 & 29.2 & 38.1 & 20.6 & 2.8 & $<0.001$ \\
\hline \multicolumn{7}{|c|}{ Would you have your daughter vaccinated against HPV infection? (\%) } \\
\hline Yes $(35.6 \%)$ & 11.6 & 28.7 & 30.6 & 23.9 & 5.2 & \multirow{2}{*}{$<0.001$} \\
\hline № $(64.4 \%)$ & 16.6 & 33.3 & 30.6 & 15.4 & 4.1 & \\
\hline
\end{tabular}

*1 - unsatisfactory, 2 - satisfactory, 3 - good, 4 - very good, 5 - excellent 
Table 3. Univariate analysis of sources of information and the level of knowledge with influences on vaccination or nonvaccination against HPV infection

\begin{tabular}{|c|c|c|c|}
\hline & \multicolumn{2}{|c|}{$\begin{array}{l}\text { Would you have your daughter vacci- } \\
\text { nated against HPV infection? }\end{array}$} & \multirow[t]{2}{*}{$\mathrm{p}$ value } \\
\hline & Yes $(35.6 \%)$ & No $(64.4 \%)$ & \\
\hline \multicolumn{4}{|l|}{ Have you heard about HPV infection? } \\
\hline Yes $(85.8 \%)$ & $35.7 \%$ & $64.3 \%$ & \multirow{2}{*}{ ns } \\
\hline No $(14.2 \%)$ & $35.4 \%$ & $64.6 \%$ & \\
\hline \multicolumn{4}{|l|}{ Which were your two main sources of information against HPV vaccination? } \\
\hline Healthcare professionals (39.1\%) & $42.1 \%$ & $57.9 \%$ & 0.009 \\
\hline Parents, relatives (3.1\%) & $35.7 \%$ & $64.3 \%$ & ns \\
\hline Friends $(11.7 \%)$ & $35.7 \%$ & $64.3 \%$ & ns \\
\hline Books, magazines $(21.9 \%)$ & $32.2 \%$ & $67.8 \%$ & ns \\
\hline Newspapers, radio, TV (32.4\%) & $33.7 \%$ & $66.3 \%$ & ns \\
\hline School (7.6) & $27.1 \%$ & $72.9 \%$ & ns \\
\hline Internet (42.9\%) & $35.8 \%$ & $64.2 \%$ & ns \\
\hline \multicolumn{4}{|l|}{ Have you requested information from your GP about HPV infection and HPV vaccination? } \\
\hline Yes $(26.4 \%)$ & $44.2 \%$ & $55.8 \%$ & \multirow{2}{*}{0.001} \\
\hline No $(73.6 \%)$ & $32.5 \%$ & $67.5 \%$ & \\
\hline \multicolumn{4}{|l|}{ Have you received information from your GP about HPV infection and HPV vaccination? (yes/no) } \\
\hline What is HPV? $(31.9 \%)$ & $44.4 \% / 32.3 \%$ & $55.6 \% / 67.7 \%$ & 0.002 \\
\hline How is HPV transmitted? (35.2\%) & $43.3 \% / 31.3 \%$ & $56.7 \% / 68.7 \%$ & 0.004 \\
\hline Nearly all cervical cancer cases are caused by HPV $(40.3 \%)$ & $43.6 \% / 30.5 \%$ & $56.4 \% / 69.5 \%$ & 0.001 \\
\hline The known types of HPV are divided into those of high risk and low risk (33.8\%) & $45.6 \% / 29.5 \%$ & $54.4 \% / 70.5 \%$ & 0.001 \\
\hline Genital warts are caused by the same types of HPV that cause cervical cancer $(27.1 \%)$ & $49.3 \% / 31.3 \%$ & $50.7 \% / 68.7 \%$ & 0.001 \\
\hline Direct skin contact in the genital area may be a medium of transmitting HPV (35.4\%) & $44.2 \% / 30.6 \%$ & $55.8 \% / 69.4 \%$ & 0.002 \\
\hline HPV infection prevention methods ( $37.2 \%)$ & $44.9 \% / 29.5 \%$ & $55.1 \% / 70.5 \%$ & 0.001 \\
\hline The existence of two vaccines $(26.0 \%)$ & $43.8 \% / 31.3 \%$ & $56.2 \% / 68.7 \%$ & 0.009 \\
\hline HPV vaccination recommendations $(32.5 \%)$ & $49.4 \% / 29.4 \%$ & $50.6 \% / 70.6 \%$ & 0.001 \\
\hline Benefits of the vaccine (32.3) & $50.0 \% / 28.4 \%$ & $50.0 \% / 71.6 \%$ & 0.001 \\
\hline Side effects of the vaccine $(26.5 \%)$ & $43.5 \% / 31.2 \%$ & $56.5 \% / 68.8 \%$ & 0.001 \\
\hline Vaccine contraindications and precautions (26.2\%) & $42.7 \% / 32.3 \%$ & $57.3 \% / 67.7 \%$ & 0.001 \\
\hline \multicolumn{4}{|l|}{ Do you have any knowledge about HPV vaccination? (yes/no) } \\
\hline Do you think that HPV vaccination is necessary? (58.7\%) & $63.9 \% / 7.6 \%$ & $36.1 \% / 92.4 \%$ & 0.001 \\
\hline $\begin{array}{l}\text { Do you think girls will be completely protected against cervical cancer after HPV } \\
\text { vaccination? }(19.3 \%)\end{array}$ & $68.8 \% / 30.4 \%$ & $31.2 \% / 69.6 \%$ & 0.001 \\
\hline $\begin{array}{l}\text { Is it better to vaccinate as many people as possible in order to protect unvaccinated } \\
\text { ones? }(48.8 \%)\end{array}$ & $65.1 \% / 15.5 \%$ & $34.9 \% / 84.5 \%$ & 0.001 \\
\hline $\begin{array}{l}\text { Should there be a cancer history in your family, would you opt for vaccination? } \\
(41.6 \%)\end{array}$ & $67.8 \% / 19.0 \%$ & $32.2 \% / 81.0 \%$ & 0.001 \\
\hline
\end{tabular}

confirming that they would. The results of the regression analysis reveal that some information provided by GP plays an important role in the decision-making process for vaccination. Thus, we identified significant associations for knowledge of prevention methods of HPV infection (OR $=7.36$; 95\% CI $1.78-30.28$, $\mathrm{p}=0.005)$ and information regarding the existence of two vaccines available for protection $(\mathrm{OR}=0.25 ; 95 \% \mathrm{CI} 0.06-0.99$, $\mathrm{p}=0.04)$. The knowledge gained about HPV vaccination from various sources seems to have a determining role, significantly influencing the parents' decision about vaccination. Thus, the lo- gistic regression model reveals significant associations for people who "believe that HPV vaccination is required" $(\mathrm{OR}=5.37 ; 95 \%$ CI 1.83-15.72, $\mathrm{p}=0.002$ ); who "think that girls will be completely protected against cervical cancer after HPV vaccination" $(\mathrm{OR}=2.18$; 95\% CI $0.92-5.14, \mathrm{p}=0.05)$; who believe that "it is better to vaccinate as many people as possible in order to protect unvaccinated ones" (OR =7.45; 95\% CI 3.04-18.28, $\mathrm{p}=0.0001)$; and for people who fear that "the existence of a cancer in the family leads them to resort to HPV vaccination" $(\mathrm{OR}=3.86$; $95 \% \mathrm{CI}$ $1.81-8.25, \mathrm{p}=0.0005)$. 
Table 4. Multivariate analysis of sources of information and level of knowledge with influences on vaccination against HPV infection *

\begin{tabular}{|c|c|c|c|}
\hline Variable & OR & $95 \% \mathrm{Cl}$ & $\mathrm{p}$ value \\
\hline Have you requested information about HPV infection and HPV vaccination from your GP? & 0.68 & $0.17-2.66$ & ns \\
\hline HPV vaccination information from healthcare professionals & 0.85 & $0.34-2.09$ & ns \\
\hline \multicolumn{4}{|l|}{ Have you received information about HPV infection and HPV vaccination from your GP? } \\
\hline What is HPV? & 4.01 & $0.85-8.78$ & ns \\
\hline How is HPV transmitted? & 0.23 & $0.04-1.11$ & ns \\
\hline Nearly all cervical cancers are caused by HPV infection. & 1.62 & $0.62-4.22$ & ns \\
\hline The known types of HPV are divided into high risk and low risk. & 0.89 & $0.30-2.58$ & ns \\
\hline Genital warts are caused by the same types of HPV that cause cervical cancer. & 0.73 & $0.24-2.19$ & ns \\
\hline Direct skin contact in the genital area may be sufficient for transmission of HPV. & 0.95 & $0.32-2.78$ & ns \\
\hline HPV infection prevention methods & 7.36 & $1.78-0.28$ & 0.005 \\
\hline Existence of two vaccines & 0.25 & $0.06-0.99$ & 0.04 \\
\hline HPV vaccination recommendations & 0.36 & $0.07-1.83$ & ns \\
\hline Benefits of the vaccine & 2.59 & $0.39-6.90$ & ns \\
\hline Side effects of the vaccine & 2.21 & $0.53-9.16$ & ns \\
\hline Contraindications and precautions of the vaccine & 0.50 & $0.09-2.53$ & ns \\
\hline \multicolumn{4}{|l|}{ Knowledge about HPV vaccination } \\
\hline Do you think HPV vaccination is necessary? & 5.37 & $1.83-5.72$ & 0.002 \\
\hline Do you think girls will be completely protected against cervical cancer after HPV vaccination? & 2.18 & $0.92-5.14$ & 0.05 \\
\hline It is better to vaccinate as many people as possible to protect unvaccinated ones? & 7.45 & $3.04-8.28$ & $<0.001$ \\
\hline Does the presence of a cancer in your family determine your decision on HPV vaccination? & 3.86 & $1.81-8.25$ & $<0.001$ \\
\hline
\end{tabular}

*Dependent variable: "Would you have your child vaccinated against HPV infection?" taken dichotomously (yes: 1, no: 0 )

Only $18.3 \%$ of the respondents felt that HPV vaccination must necessarily be done through national campaigns in school and that the vaccine should be available free of charge.

To the question "At what age is the first dose of HPV vaccine recommended?", $34.1 \%$ of the respondents correctly answered 12-14 years, while $32.8 \%$ specified the best moment being before the start of sexual activity. Nearly $10 \%$ did not know how to answer this question.

In terms of developing an information campaign about the vaccine and vaccination, the majority of parents insisted that more information about HPV infection or vaccination should be provided by healthcare professionals $(86.3 \%)$, but one quarter also mentioned the need for more active involvement of healthcare professionals in schools to ensure more efficient education about transmitted diseases. Such a campaign should pursue the benefits of vaccination ( $68.3 \%$ ), the risks of not being vaccinated (57.5\%), vaccine effectiveness $(58.7 \%)$, and the side effects of vaccination $(61.3 \%)$.

\section{DISCUSSION}

The study was conducted on a sample of parents of pupils' attending 5-8 grades, chosen from three schools in a city in Central Romania. The study assessed the level of parental knowledge about HPV infection and HPV vaccination including the level of information and identification of barriers to implementation of a vaccination strategy.
HPV vaccination programmes launched in Romania in recent years resulted in failure due to very low vaccination rates. Our study brings data on the current state of knowledge of parents; it identifies sources from which they could get the relevant information about the infection/vaccination, and it identifies the ratio of people who would intend to have their daughters vaccinated. These data can provide support for implementing the best HPV vaccination strategies in Romania.

Since the introduction of global vaccination, the rate of vaccination coverage has varied from country to country. The acceptance rate of vaccination in Europe has been generally high, e.g. with a value of $76 \%$ in England by 2010 , and $81 \%$ in Scotland by 2011 . These high rates were mainly due to vaccination programmes in schools (13).

In France, where there has been no such programme, three-dose vaccination coverage was $28.5 \%$ by 2009 (14).

Following projects outside the European area, vaccine administration rates varied. In Australia, where vaccination was implemented in schools in 2007 , the rate of take up was $72 \%$, while in developing countries that adopted pilot centres to assess the feasibility of vaccination programmes, administration rates varied from $70 \%$ to $90 \%$ (15). These studies demonstrate that well-organized national projects such as vaccination programmes in schools, with well informed persons involved (doctors, parents, pupils), have resulted in very high vaccination rates.

Our study revealed a positive attitude of the population towards the prevention of infectious diseases. In terms of health problems occurring in children, $93.4 \%$ of respondents turn to healthcare 
professionals and $67 \%$ consider prevention of serious diseases as a mandatory approach. About $10 \%$ of the respondents did not agree with any vaccine, preferring to have their children develop their own immunity through natural infection. Many of the parents know at least two vaccines that are included in NIP (86\%), and acknowledged that their child received at least one vaccine within NIP (89.1\%). According to the parents, the reasons for which they do not want to have their child vaccinated are fear of side effects, doubts regarding the safety or efficacy of vaccines, the new ones in particular, and because of poor information about the vaccine.

Regarding the attitude towards the prevention of infectious diseases, we noticed that the parents who accept vaccination are more educated, especially the mothers. Regarding vaccination in general, parents who do not accept vaccinations for their children often have limited knowledge about vaccine-preventable diseases and vaccines, and their decisions are often based on the recommendations of GP.

Regarding the way of transmission of the infection, 85-91.4\% of parents surveyed in our study considered heterosexual or homosexual relations, and $57.6-70 \%$ considered the way of skin/ intimate touch. Incorrect answers were mentioned (blood transfusions, unsterilized needles, contaminated objects), suggesting the need for more accurate information on this determining factor of the spread of HPV infection.

The research results showed an average level of knowledge based on answers to all the types of questions. On our assessment scale from 1 (insufficient) to 5 (excellent), $31.4 \%$ of respondents had a level of knowledge about HPV infection ranging from very good (4) to excellent (5), compared to $22.9 \%$ with the level of knowledge about HPV vaccination according to the same assessment criteria: 4 (very good) to 5 (excellent). On the other hand, $37.0 \%$ and $46.5 \%$ of the respondents had an insufficient and sufficient level of knowledge about the infection and vaccination, respectively. Women proved to have wider knowledge about HPV infection, given the well-known relationship of infection-cervical cancer specific to females, but knowledge about vaccination was similar between the genders.

Not surprisingly, we found that GP is a crucial source of information about HPV infection and HPV vaccination. This finding is consistent with the data in the literature, where studies demonstrate the important role of GP, GP's recommendation being the main decisive factor in vaccination $(13,16)$.

Of those who received information about the infection and vaccination, the two most trusted sources were healthcare professionals ( $42.8 \%$ and $39.1 \%$ of the respondents) and the Internet ( $42.3 \%$ and $42.9 \%$ ), followed by the media and specialized books. Information provided by healthcare professionals proved to be more relevant than that found on the Internet, a fact proved by higher percentages in line with level 4 (very good) or 5 (excellent) of knowledge. The relevance of the information retrieved from the Internet is questionable; we identified studies that mentioned that the Internet could cause parents to refuse the vaccine for their daughter $(17,18)$.

While the quality of information on any topic related to HPV derived from textbooks is undeniable, that of the information provided by the media (TV, radio, newspapers) is questionable; it does not increase the quality of knowledge, but these sources of information can still often influence, deliberately or not, the population's attitude towards vaccination. The studies of Pența and Baban explored the positive and negative discussions about vaccination expressed in Internet discussion forums and the information provided by the media. The results showed that the ambivalence and uncertainty derived from the pros and cons, along with criticism of suboptimal organization, had a role in the failure of HPV vaccination programmes applied in Romania (19).

In this study, we observed that the main reason for HPV vaccination was the reduction of HPV infection risk and cervical cancer protection. However, in a very high percentage, (64.4\%) parents would not have their daughter vaccinated because of concerns about the safety and efficacy of the vaccine, its impact on fertility, fear of side effects, lack of confidence in a new vaccine, conflicting information provided by healthcare professionals, and limited information about HPV vaccination. Understanding the reasons of parents regarding vaccination of their daughters can help public health authorities to implement educational programmes to increase the absorption of HPV vaccination. Our results are similar to those identified in foreign studies (20-23).

By univariate and multivariate analysis (Tables 3 and 4), we identified the cumulative conditions that help parents decide to have their child vaccinated against HPV infection. Our results with respect to the two main sources of information on HPV vaccination show significant association $(p=0.009)$ only in the case of healthcare professionals, not in the case of other sources of information. This proves that GP and the school physician have a significant role in parental attitudes towards vaccination and can be an influential source of information for parents. Thus, we can mention that to address public concerns regarding vaccination, targeted educational campaigns would have a good chance of success if they were conducted through GPs and the school physicians, who should be well trained by public health authorities. The quality of information depends on the experience of the doctor and the prevalence of oncological diseases of the anogenital type that exists among the patients of a particular doctor.

As our study proves, GP must provide details especially on existing prevention methods, the existence of vaccines, recommendations, benefits and side effects because these are the information best perceived or highly regarded by the parents.

The attitude of doctors must be objective, as it is their responsibility to provide all the necessary information about HPV infection or vaccination, and ultimately, it is up to parents to make an informed decision on HPV vaccination (24-26).

According to a set of questions in our study, $58.7 \%$ of parents believe that HPV vaccination is required, and of these $64 \%$ would have their daughter vaccinated. Also, $48.8 \%$ think it is better to vaccinate as many people as possible to protect unvaccinated ones. The existence of a cancer in the family would greatly influence the parent to decide on HPV vaccination. The study by Rosenthal et al. showed that less educated parents suffering from sexually transmitted diseases are strongly influenced by these experiences when deciding to have their children vaccinated against HPV (27).

Studies have shown that in girls aged 10-14 years, the body's immune response to HPV vaccination, measured by specific HPV serum antibody titer, is two times higher than in girls and women in the age group of 15-25. Taking into account that it is preferable that HPV vaccination should be done before the start of sexual life to prevent a possible infection at the time of the first sexual intercourse, countries that introduced prevention vaccination against cervical cancer in their national programmes 
decided that routine vaccination should be carried out at the age of 10-14 years $(28,29)$.

In our study, $34.1 \%$ of the respondents mentioned the right age, $12-14$ years; $32.8 \%$ answered that vaccination should be done before the start of sexual activity, while almost $10 \%$ did not know how to answer this question.

Our study has limitations. The survey was conducted on a group of parents of pupils in three secondary schools randomly selected from three different districts of the city, without applying any formula of probability sampling, parents with socio-demographic characteristics unknown at the beginning, thus, the generalization of the results should be made with caution. However, the big enough sample size and high response rate reduce the consequences of this limitation. On the other hand, pupils from these schools may come from families of parents from all areas of the city with heterogeneous socio-demographic characteristics. Also the easiest procedure for parents to participate in the survey, selfadministration of the questionnaire, is another limitation because it is not known if it was the parent indeed who completed the questionnaire. The internal validity of the questionnaire based on the answers could refute or confirm this. Data collection in this cross-sectional study was conducted at the end of 2014, at some time since the launch of HPV vaccination campaigns in Romania, and the perceived barriers to vaccination may have changed in time.

\section{CONCLUSIONS}

The parents showed the average level of knowledge about HPV infection and HPV vaccination. The ratio of parents who would have their daughter vaccinated is low, about one third, and vaccination refusal derives from the fear of side effects and because of little and unclear information provided by people involved. From the parents' points of view, GP can play a key role in increasing the acceptance rate of HPV vaccination in order to anticipate the implementation of another vaccination programme. The involvement of GP in matters of health education indicates the need for educational strategies by providing clear and transparent information on the advantages and disadvantages of HPV vaccination aimed at parents and students. Healthcare professionals should be trained to use appropriate communication strategies that can help reduce the fear of side effects and increase confidence in vaccination among parents.

\section{Acknowledgements}

This paper was published within the frame of the European Social Found, Human Resources Development Operational Programme 2007-2013, project no. POSDRU/159/1.5/S/136893.

We are grateful to the Mureş County School Inspectorate, to all teachers and educational coordinators from the three schools included in the study as well as to the pupils and their parents for their support, help and cooperation in completing the questionnaires.

\section{Conflict of Interests}

None declared

\section{Contribution of Authors}

VS designed the study, prepared the material, statistically processed and analyzed the data, interpreted the results, drafted and edited the manu- script. MD coordinated and monitored the activities of the study and critically reviewed the manuscript. MT analyzed the data and critically reviewed the manuscript. SM reviewed the material used for the study and critically reviewed the manuscript. AG contributed to the collection and introduction of the questionnaires in the database of the study. All authors have read and approved the final manuscript.

\section{REFERENCES}

1. Walboomers JM, Jacobs MV, Manos MM, Bosch FX, Kummer JA, Shah $\mathrm{KV}$, et al. Human papillomavirus is a necessary cause of invasive cervical cancer worldwide. J Pathol. 1999 Sep;189(1):12-9.

2. Bosch FX, Lorincz A, Muñoz N, Meijer CJ, Shah KV. The causal relation between human papillomavirus and cervical cancer. J Clin Pathol. 2002 Apr;55(4):244-65.

3. Palefsky JM, Giuliano AR, Goldstone S, Moreira ED Jr, Aranda C, Jessen $\mathrm{H}$, et al. HPV vaccine against anal HPV infection and anal intraepithelial neoplasia. N Engl J Med. 2011 Oct 27;365(17):1576-85.

4. Muñoz N, Bosch FX, de Sanjosé S, Herrero R, Castellsagué X, Shah $\mathrm{KV}$, et al.; International Agency for Research on Cancer Multicenter Cervical Cancer Study Group. Epidemiologic classification of human papillomavirus types associated with cervical cancer. N Engl J Med. 2003 Feb 6;348(6):518-27.

5. International Agency for Research on Cancer. GLOBOCAN 2012: estimated cancer incidence, mortality and prevalence worldwide in 2012 [Internet]. Lyon: IARC; 2016 [cited 2016 Mar 8]. Available from: http:// globocan.iarc.fr.

6. Centers for Disease Control and Prevention (CDC). Recommendations on the use of quadrivalent human papillomavirus vaccine in males - Advisory Committee on Immunization Practices (ACIP), 2011. MMWR Morb Mortal Wkly Rep. 2011 Dec 23;60(50):1705-8.

7. Hendry M, Lewis R, Clements A, Damery S, Wilkinson C. "HPV? Never heard of it!": a systematic review of girls' and parents' information needs, views and preferences about human papillomavirus vaccination. Vaccine. 2013 Oct 25;31(45):5152-67.

8. Paavonen J, Naud P, Salmerón J, Wheeler CM, Chow SN, Apter D, et al.; HPV PATRICIA Study Group. Efficacy of human papillomavirus (HPV)-16/18 AS04-adjuvanted vaccine against cervical infection and precancer caused by oncogenic HPV types (PATRICIA): final analysis of a double-blind, randomised study in young women. Lancet. $2009 \mathrm{Jul}$ 25;374(9686):301-14.

9. McCormack PL, Joura EA. Quadrivalent human papillomavirus (types $6,11,16,18)$ recombinant vaccine (Gardasil () ): a review of its use in the prevention of premalignant genital lesions, genital cancer and genital warts in women. Drugs. 2010 Dec 24;70(18):2449-74.

10. Cervarix (human papillomavirus bivalent vaccine, recombinant intramuscular injection) product information. Research Triangle Park (NC): GlaxoSmithKline; 2009.

11. Pența MA, Băban A. Dangerous agent or saviour? HPV vaccine representations on online discussion forums in Romania. Int J Behav Med. 2014 Feb;21(1):20-8.

12. Craciun C, Baban A. "Who will take the blame?": understanding the reasons why Romanian mothers decline HPV vaccination for their daughters. Vaccine. 2012 Nov 6;30(48):6789-93.

13. Hopkins TG, Wood N. Female human papillomavirus (HPV) vaccination: global uptake and the impact of attitudes. Vaccine. $2013 \mathrm{Mar}$ 25;31(13):1673-9.

14. Fagot JP, Boutrelle A, Ricordeau P, Weill A, Allemand H. HPV vaccination in France: uptake, costs and issues for the National Health Insurance. Vaccine. 2011 Apr 27;29(19):3610-6.

15. LaMontagne DS, Barge S, Le NT, Mugisha E, Penny ME, Gandhi S, et al. Human papillomavirus vaccine delivery strategies that achieved high coverage in low- and middle-income countries. Bull World Health Organ. 2011 Nov 1;89(11):821-830B.

16. Kessels SJ, Marshall HS, Watson M, Braunack-Mayer AJ, Reuzel R, Tooher RL. Factors associated with HPV vaccine uptake in teenage girls: a systematic review. Vaccine. 2012 May 21;30(24):3546-56.

17. Hughes J, Cates JR, Liddon N, Smith JS, Gottlieb SL, Brewer NT. Disparities in how parents are learning about the human papillomavirus vaccine. Cancer Epidemiol Biomarkers Prev. 2009 Feb;18(2):363-72. 
18. Cates JR, Shafer A, Carpentier FD, Reiter PL, Brewer NT, McRee AL, et al. How parents hear about human papillomavirus vaccine: implications for uptake. J Adolesc Health. 2010 Sep;47(3):305-8.

19. Penţa MA, Băban A. Mass media coverage of HPV vaccination in Romania: a content analysis. Health Educ Res. 2014 Dec;29(6):977-92.

20. Giambi C, D'Ancona F, Del Manso M, De Mei B, Giovannelli I, Cattaneo C, et al.; Local Representatives for VALORE. Exploring reasons for non-vaccination against human papillomavirus in Italy. BMC Infect Dis. 2014 Nov 11;14:545. doi: 10.1186/s12879-014-0545-9.

21. Firenze A, Marsala MG, Bonanno V, Maranto M, Ferrara C, Giovannelli $\mathrm{L}$, et al. Facilitators and barriers HPV unvaccinated girls after 5 years of program implementation. Hum Vaccin Immunother. 2015;11(1):240-4.

22. Hanley SJ, Yoshioka E, Ito Y, Konno R, Hayashi Y, Kishi R, et al. Acceptance of and attitudes towards human papillomavirus vaccination in Japanese mothers of adolescent girls. Vaccine. 2012 Aug 24;30(39):5740-7.

23. Haesebaert J, Lutringer-Magnin D, Kalecinski J, Barone G, Jacquard AC, Régnier V, et al. French women's knowledge of and attitudes towards cervical cancer prevention and the acceptability of HPV vaccination among those with 14 - 18 year old daughters: a quantitative-qualitative study. BMC Public Health. 2012 Nov 27;12:1034. doi: 10.1186/14712458-12-1034.
24. Riedesel JM, Rosenthal SL, Zimet GD, Bernstein DI, Huang B, Lan $\mathrm{D}$, et al. Attitudes about human papillomavirus vaccine among family physicians. J Pediatr Adolesc Gynecol. 2005 Dec;18(6):391-8.

25. Kahn JA, Zimet GD, Bernstein DI, Riedesel JM, Lan D, Huang B, et al. Pediatricians' intention to administer human papillomavirus vaccine: the role of practice characteristics, knowledge, and attitudes. J Adolesc Health. 2005 Dec;37(6):502-10.

26. Patel PR, Berenson AB. Sources of HPV vaccine hesitancy in parents Hum Vaccin Immunother. 2013 Dec;9(12):2649-53.

27. Rosenthal SL, Rupp R, Zimet GD, Meza HM, Loza ML, Short MB, et al. Uptake of HPV vaccine: demographics, sexual history and values, parenting style, and vaccine attitudes. J Adolesc Health. 2008 Sep;43(3):239-45.

28. European Centre for Disease Prevention and Control. Guidance for the introduction of HPV vaccines in EU countries: Stockholm, January 2008. Stockholm: ECDC; 2008.

29. Human papillomavirus vaccines. WHO position paper. Wkly Epidemiol Rec. 2009 Apr 10;84(15):118-31.

Received: January 30, 2015 Accepted in revised form June 11, 2015 